Conclusions: During the 5-year follow-up period, patients with SpA responded well to TNFi and the response rate increased over time. Tuberculosis was the most common SAE in this registry therefore surveillance of TB should be done.

Disclosure of Interest: P. Chiowchanwisawakit Grant/research support from: The Thai Rheumatism Association, W. Katchamart: None declared, P. Chevaisrakul: None declared, P. Narongroeknawin: None declared, W. Louthrenoo: None declared, M. Osiri: None declared

DOI: 10.1136/annrheumdis-2017-eular.5694

\section{AB0701 THE REAL-LIFE USE OF GOLIMUMAB IN PATIENTS WITH IMMUNE-MEDIATED RHEUMATIC DISEASES: ONE YEAR RESULTS OF THE GO-PRACTICE STUDY}

R.-M. Flipo ${ }^{1}$, F. Tubach ${ }^{2}$, J. Ouaniche ${ }^{3}$, P. Goupille ${ }^{4}$, E. Lespesailles ${ }^{5}$, N. Gouyette ${ }^{6}$, P. Bertin ${ }^{7}$, B. Fautrel ${ }^{8} .{ }^{1}$ Rheumatology, CHU Roger Salengro, Lille, Lille: ${ }^{2}$ Epidemiology Departement \& Clinical Research, CHU Pitié Salpêtrière, Paris: ${ }^{3}$ Private practice, Private practice, Toulon, France, Toulon; ${ }^{4}$ Rheumatology, CHU Tours, Tours; ${ }^{5}$ Rheumatology, CHR Orléans, Orléans, France: ${ }^{6}$ Rheumatology, Msd France, Courbevoie Cedex: ${ }^{7}$ Rheumatology, CHU Limoges, Limoges; ${ }^{8}$ Rheumatology, CHU Pitié Salpêtrière, Paris, Paris, France

Background: The GO-PRACTICE study was initiated to describe the use of Golimumab (GLM), a human anti-TNF $\alpha$ monoclonal antibody, in patients with rheumatoid arthritis (RA), psoriatic arthritis (PsA), and ankylosing spondylitis (AS) in French clinical practice.

Objectives: The primary objective of this interim analysis was to assess the persistence of GLM at 1-year.

Methods: Observational, multicenter, prospective, national study. Adult patients with RA, PsA and AS were included consecutively at GLM after the decision for GLM therapy has been taken or at least after GLM initiation, and followed-up for 2 years. We present here baseline characteristics for overall population $(n=754)$ and interim results for patients with 1-year follow-up ( $n=228$ patients with available data regarding persistence of GLM)

Results: A total of 754 patients (134 sites) were included between January 2015 and March 2016. Most of them had AS (64\%), and 22\% and 13\% had RA and PsA, respectively. Mean age was $46 \pm 13$ years and $61 \%$ were female. Almost $37 \%$ had received prior biotherapy.

Nearly all patients (99\%) were prescribed GLM as 50 mg-monthly injections. GLM was mostly co-prescribed with other antirheumatic treatments (84\%).

Of the 163 patients with available data at strictly 1 -year, $56.4 \%$ were still treated with GLM; (61.9\% in biotherapy-naïve patients); the persistence rate was similar across the three groups. The Kaplan-Meier duration curves of GLM are presented in figure 1. The main reason for GLM discontinuation was primary non-response, reported in $42 \%$ of patients.

Among patients who continued GLM treatment, a meaningful improvement in disease activity was observed at 1 -year in $71.9 \%$ of RA, $63.2 \%$ of PsA and $68.0 \%$ of AS patients. Patients-reported outcomes, including pain and functional disability, also showed improvement

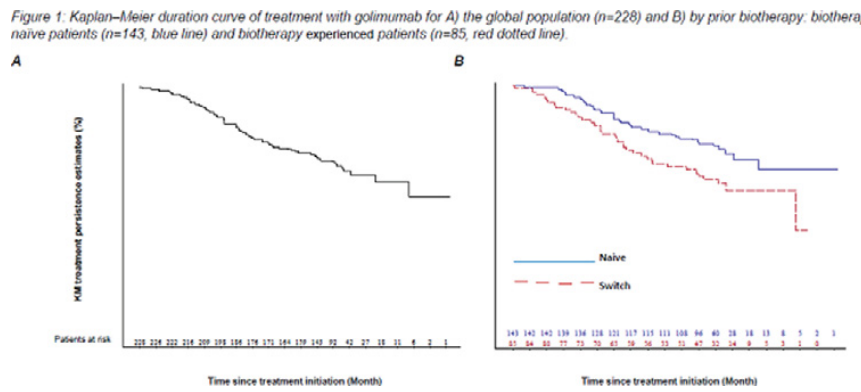

Conclusions: In real-life practice in France, GLM was prescribed according to recommendations in terms of dosage and therapeutic strategy. One-year interim analysis, performed in one third of the cohort, suggests that GLM treatment is associated with clinical improvements leading to persistence of treatment. These results need to be confirmed in the final overall analysis planned in 2018.

Disclosure of Interest: R.-M. Flipo: None declared, F. Tubach: None declared, J. Ouaniche: None declared, P. Goupille: None declared, E. Lespesailles: None declared, N. Gouyette Employee of: MSD, P. Bertin: None declared, B. Fautrel: None declared

DOI: 10.1136/annrheumdis-2017-eular.4073

\section{AB0702 IMPROVEMENT OF FATIGUE IN PATIENTS WITH SPONDYLOARTHRITIS TREATED WITH ANTI-TNF THERAPY: A PROSPECTIVE STUDY IN A REAL-LIFE SETTING}

S. Desouches, E. Gaigneux, K. Louati, L. Lemeunier, C. Beauvais, J. Sellam, F. Berenbaum. Rheumatology, APHP Saint-Antoine, paris, France

Background: Besides randomized controlled trials evaluating biologic agents on fatigue, the impact of anti-TNF therapy on this crucial symptom has been poorly assessed in a real-life setting (1).

Objectives: To assess the early effect of etanercept (ETN) on fatigue-related outcomes in spondyloarthritis ( $\mathrm{SpA}$ ) patients in a real-life setting.

Methods: This prospective study included patients with active SpA fulfilling ASAS 2009 axial or peripheral criteria requiring an anti-TNF. All patients were treated with ETN 50mg weekly. BASDAI, BASFI, functional assessment of chronic illness therapy-fatigue (FACIT-F) ( 0 maximum and 52 the minimum of fatigue) and visual analogic scale of fatigue (VAS-F) ( 0 the minimum -100 maximum of fatigue) were assessed at inclusion at the time of ETN beginning (M0) and $4 \pm 1$ months later (M4).

The primary outcome was the MO-M4 change of VAS-F. The secondary outcomes were i) the M0-M4 change of FACIT-F ii) the frequency of patients who met improvement according to FACIT-F (defined as the minimal clinically important difference of FACIT-F corresponding to a 4-points decrease (FACIT-F responders). To determine whether fatigue change was related to disease activity improvement, a correlation between M0-M4 changes of BASDAI and VAS-F or FACIT-F was determined.

Results: $30 \mathrm{SpA}$ patients were enrolled $60 \%$ women, mean age \pm standard deviation $39 \pm 8$ years-old, axial SpA $83 \%$, mean BMI $26 \pm 4,80 \%$ ETN as a 1 st line). Mean BASDAI improved at M4 (M0 48 \pm 20 versus M4 $36.5 \pm 22 ; p=0.04$ ) as well as VAS-F (M0 $69 \pm 18$ vs M4 $52 \pm 24 ; p=0.01)$. The frequency of patients having VAS-F $>50 / 100$ was $86 \%$ at $\mathrm{M0}$ and decreased at $36 \%$ at M4. Conversely, no significant change was observed concerning FACIT-F (M0 24.5 \pm 24 versus M4 28.8 $\pm 11: \mathrm{p}=0.36$ ). At M4, 64\% patients were FACIT-F responders. FACIT-F and VAS-F MO-M4 changes were highly correlated $(r=0.78, p<0.0001)$.

Despite no correlation between BASDAI and FACIT-F M0-M4 changes ( $r=0.36$, $\mathrm{p}=0.1$ ), a trend was observed for BASDAI and VAS-F M0-M4 changes in the same fashion ( $r=0.36, p=0.07$ ). Interestingly, there was no baseline clinical characteristic associated with subsequent better fatigue improvement.

Conclusions: This real-life study investigating the early effect of etanercept therapy on fatigue in SpA patients showed that fatigue (according to VAS-F) significantly improved while effect on FACIT-F was less pronounced. This improvement was explained, only in part, by disease activity improvement. References:

[1] Chauffier K, et al Clin Exp Rheumatol. 2013;31:864-70.

Acknowledgements: Grant from Pfizer.

Disclosure of Interest: None declared

DOI: 10.1136/annrheumdis-2017-eular.2735

\section{AB0703 IMPACT OF ANTI-TNF AGENTS ON PATIENT-REPORTED OUTCOMES IN SPONDYLOARTHRITIS: A SYSTEMATIC REVIEW OF THE LITERATURE AND META-ANALYSIS}

S. Laclau ${ }^{1}$, A. Constantin ${ }^{1,2}$, A. Cantagrel ${ }^{1,2}$, T. Barnetche $^{3}$,

A. Ruyssen-Witrand ${ }^{1,4}$, Y. Degboe ${ }^{1,2} .{ }^{1}$ Rheumatology Center, Hospital Pierre

Paul Riquet, Toulouse University Hospital; ' CPTP, INSERM UMR 1043,

Toulouse; ${ }^{3}$ Rheumatology Department, Fhu Acronim, Bordeaux University

Hospital, Bordeaux; ${ }^{4}$ Pharmaco-épidémiologie, Evaluation de l'utilisation et du risque médicamenteux, INSERM UMR 1027, Toulouse, France

Background: Disability, alteration in quality of life and fatigue are frequently reported in spondyloarthritis $(\mathrm{SpA})$. Anti-TNF demonstrated clinical efficacy in $\mathrm{SpA}$. However efficacy on patient-reported outcomes (PROs) may differ from medical assessment.

Objectives: To assess the impact of anti-TNF on quality of life, disability and fatigue reported by SpA patients.

Methods: Design: systematic review and meta-analysis of the literature. Data sources: two authors (SL and YD) independently screened PubMed-Medline, Cochrane library and EMBASE databases until November 2016. Key words: ("Patient reported" OR "quality of life" OR fatigue OR FACIT) AND (spondyloarthritis OR "psoriatic arthritis" OR "ankylosing spondylitis") AND (anti-TNF OR certolizumab OR etanercept OR adalimumab OR infliximab OR golimumab). Articles selection: randomized controlled trials (RCTs), published in English, assessing efficacy of anti-TNF on PROs, in ankylosing spondylitis (AS), psoriatic arthritis (PsA) or SpA according to the ASAS criteria. Data collected: fatigue assessed by FACIT score, quality of life assessed by Short Form 36 (SF36) mental and physical component or by Health AssessementQuestionnary Disability Index (HAQ). Data analysis: Article quality was evaluated by the JADAD scale. For SF36 and HAQ outcomes, pooled variations at 12 and 24 weeks were computed by meta-analysis. Heterogeneity was measured by $\mathrm{I}^{2}$ index.

Results: Of the 604 articles identified, 37 references were eligible for systematic review and 13 for meta-analysis. Our systematic review identified 10 RCTs concerning AS, 20 concerning PsA and 7 concerning axial SpA. However due to the heterogeneity in available statistical data, references eligible for meta-analysis were mainly related to PsA.

$\mathrm{HAQ}$ assessment was available for a meta-analysis in 8 studies. HAQ was significantly improved at 12 and 24 weeks with anti-TNF. The impact on HAQ variation at week 24 was -0.29 points $[95 \% \mathrm{Cl}:-0.37,-0.22]$. Heterogeneity was important $\left(l^{2}=57 \%\right.$; see figure).

Ten studieswere eligible for a meta-analysis of anti-TNF effect on SF36 mental form. An improvement was observed at 12 and 24 weeks, although superior at 24 weeks. The effect at week 24 was 2.78 [95\% Cl: $1.87-3.68]$, without heterogeneity $\left(1^{2}=0 \%\right.$; see figure). 
Twelve studies were eligible for a meta-analysis of anti-TNF effect on SF36 physical form. We observed a similar and significant improvement at 12 and 24 weeks. The effect at week 24 was 6.74 [95\% Cl: $5.34-8.13]$, with an important heterogeneity $\left(\mathrm{I}^{2}=84 \%\right.$; see figure)

Fatigue was evaluated in 3 studies. Adalimumab induced a significant improvement in FACIT score at 12 and 24 weeks in one study. Two studies using different scores (Fatigue Assessment Scale, BASDAl fatigue item) to assess certolizumab effect highlighted similar findings: an early improvement in fatigue at week 12, remaining significant and stable at week 24 .
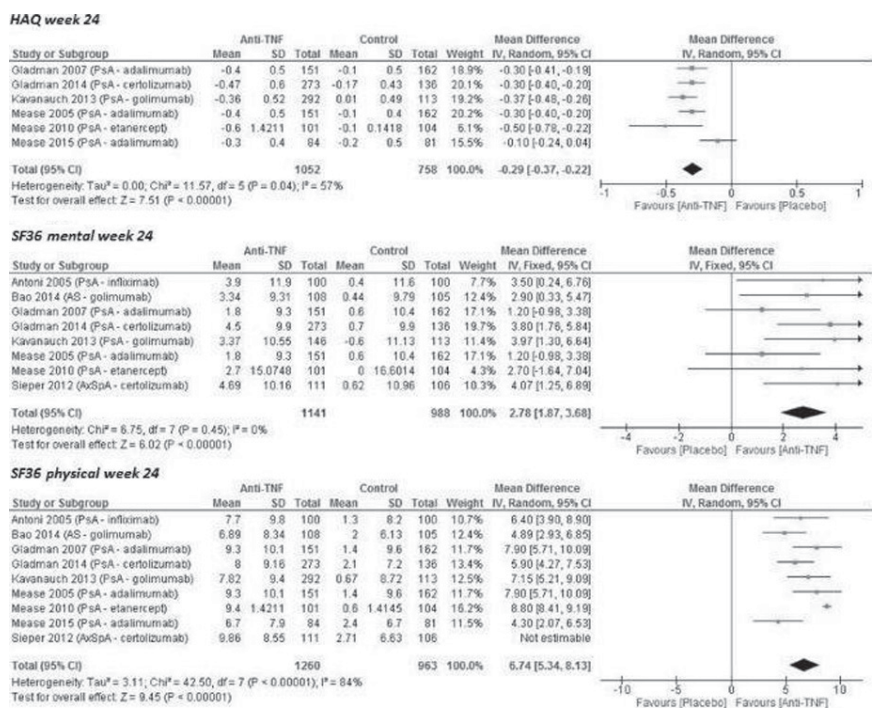

Conclusions: Anti-TNFs agents significantly improve disability, quality of life and fatigue in patients with PsA.

Acknowledgements: Abbvie France pharmaceutical company provided logistic support by organizing a meta-analysis methods workshop, but played no further role in the project.

Disclosure of Interest: None declared

DOI: 10.1136/annrheumdis-2017-eular.5268

\section{AB0704 HIP ARTHROPLASTY IN PATIENTS WITH ANKYLOSING SPONDYLITIS - CLINICAL AND FUNCTIONAL EFFICIENCY}

S. Lapshina ${ }^{1,1}$ I. Akhtyamov ${ }^{1,2}$, I. Gilmutdinov ${ }^{2}$, L. Myasoutova ${ }^{1}{ }^{1}{ }^{1}$ Kazan State Medical University; ${ }^{2}$ Republic Clinical Hospital, Kazan, Russian Federation

Objectives: To evaluate the results of the hip joints replacement in patients with $\mathrm{SpA}$ under the dynamic supervision of a rheumatologist and orthopedic within the first year after the operation.

Methods: As part of special program for rheumatology patients hip endoprosthesis was done in 12 patients (mean age - 44,2 $\pm 15,3$ years) with SpA, 8 of them with ankylosing spondylitis (AS) and 4 with psoriatic arthritis (PsA). Duration of the disease $-13,3 \pm 7,9$ years, positive for HLA B27 in $9(75 \%)$ patients. High activity for ASDAS was at $58.3 \%$ of the patients. Took NSAIDs at the time of the operation - $11(91.6 \%)$ patients, sulfasalazine $5(41.6 \%)$, methotrexate- $2(16.7 \%) .1(8.3 \%)$ patient received etanercept, $1(8.3 \%)$ patient - infliximab. Dynamic observation of rheumatologist and orthopedic was carried out before, just after surgery, after 6 and 12 months, with the assessment of VAS, BASDAI, ASDAS, BASFI.

Results: The reduction of pain intensity on the VAS was observed in the first month after the surgery $(47,3 \pm 18,6 \mathrm{~mm})$, initially it was $74,0 \pm 24,1 \mathrm{~mm}, 42.5 \pm 9$ after 6 months $(p<0.05)$, after 12 months - up to $22,5 \pm 9,9 \mathrm{~mm}(\mathrm{p}<0.05)$. ASDAS significantly $(p<0.05)$ reduced from $2,94 \pm 2,01$ to $1,68 \pm 1,35$ - in 6 months and $1,26 \pm 0,88$ - 12 months after operation; BASDAl: from $6,24 \pm 3,91$ to $2,75 \pm 2,20-6$ months, $2,65 \pm 1,53$ at 1 year follow-up. BASFI index before surgery - $5,48 \pm 3,29$, 6 months $-2,78 \pm 2,31,1$ year $-2,32 \pm 1,60$ points. No complications after surgery were registered.

Conclusions: Hip joints endoprosthesis in patients with SpA is effective not only in improving functional ability and pain relief, but also a reduction of disease activity. Dynamic rheumatologist observation in perioperative period leads to positive dynamics in relation to the activity of $\mathrm{SpA}$ and quality of life of patients during the first year after surgery

Disclosure of Interest: None declared

DOI: 10.1136/annrheumdis-2017-eular.3966

\section{AB0705 CONTINUED EFFECTIVENESS OF A BIOSIMILAR ADALIMUMAB AFTER STOPPAGE OF INITIAL TREATMENT IN PATIENTS WITH ANKYLOSING SPONDYLITIS}

S. Bandyopadhyay ${ }^{1}$, A. Ray ${ }^{2}$, R.N. Sarkar ${ }^{3}$, S. Dash ${ }^{1}$, S. Mondal ${ }^{1} .{ }^{1}$ Medicine, Apollo Gleneagles Hospital; ${ }^{2}$ Medicine, Fortis Hospital, Kolkata; ${ }^{3}$ Medicine, Calcutta Medical College, Kolkata, India

Background: Adalimumab, an anti TNF- $\alpha$ agent, has been proven to be safe and effective in treatment of ankylosing spondylitis (AS). A biosimilar adalimumab was approved for use by Indian regulators in 2014. It is a "fingerprint match" of the reference adalimumab in terms of purity, potency, safety and clinical efficacy. ${ }^{1,2}$ In the absence of availability of adalimumab in India, this biosimilar adalimumab currently serves as an accessible, cost-effective option for treatment of AS patients.

Objectives: This retrospective analysis evaluates effectiveness of biosimilar adalimumab (bADA), in terms of disease activity, safety and outcomes in real-life Indian AS patients treated for initial 24 weeks and then followed for next 24 weeks off biologic treatment.

Methods: Medical records of AS patients with Bath Ankylosing Spondylitis Disease Activity Index (BASDAI) and Bath Ankylosing Spondylitis Functional Index $(B A S F I)>4$, who were prescribed bADA therapy between January to December 2015 were analysed. For patients, who stopped bADA treatment after 24 weeks, standard AS outcome-measurement scores including ESR, CRP, BASDAI, BASFI, and Health Assessment Questionnaire (HAQ) at baseline, week 24 and at week 48 were measured to evaluate ongoing efficacy, were compared using paired Student's T-test. Patients were allowed to continue methotrexate and salazopyrin as part of routine medical care.

Results: During the study period, 52 AS patients were prescribed bADA 40 $\mathrm{mg} \mathrm{s} / \mathrm{c} ; 24$ of these patients, who had stopped treatment after 6 months, were considered for this analysis. Mean age for this group was $36.57 \pm 10.81$ years; 10 females. At the end of 24 weeks' treatment, there were significant reductions in levels of inflammatory markers ESR, CRP, as well as in BASDAI, $\mathrm{BASFI}$ and $\mathrm{HAQ}$ scores. Eight patients continued to receive methotrexate and 8 patients sulfasalazine as concomitant medications. After week 48 (24 weeks post stoppage), BASDAI and BASFI scores did not deteriorate despite discontinuation of bADA treatment. The patients' HAQ scores were also indicative of similar trends of continuing improved health status post the therapy.

Table 1. Disease activity scores and patient outcomes at 24 weeks after completion of biosimilar adalimumab therapy

\begin{tabular}{lccccc}
\hline Parameters & Baseline & $\begin{array}{c}\text { Week 24 } \\
\text { (last dose) }\end{array}$ & $\begin{array}{c}\text { P value } \\
\text { (baseline - } \\
\text { week 24) }\end{array}$ & $\begin{array}{c}\text { Week 48 } \\
\text { (24 weeks bADA } \\
\text { free period) }\end{array}$ & $\begin{array}{c}\text { P value } \\
\text { (baseline - } \\
\text { week 48) }\end{array}$ \\
\hline BASFI & $8.35 \pm 0.72$ & $2.87 \pm 0.77$ & $\mathrm{p}<0.001$ & $2.55 \pm 0.65$ & $\mathrm{p}<0.001$ \\
BASDAI & $7.70 \pm 0.84$ & $2.45 \pm 0.58$ & $\mathrm{p}<0.001$ & $2.41 \pm 0.58$ & $\mathrm{p}<0.001$ \\
ESR & $49.50 \pm 28.78$ & $13.97 \pm 11.19$ & $\mathrm{p}<0.001$ & $30.33 \pm 26.23^{\wedge}$ & $\mathrm{p}=0.02$ \\
CRP & $19.71 \pm 12.24$ & $3.58 \pm 3.6$ & $\mathrm{p}<0.001$ & $6.13 \pm 9.41$ & $\mathrm{p}<0.001$ \\
HAQ (Pain) & $67.71 \pm 7.22$ & $27.08 \pm 8.2$ & $\mathrm{p}<0.001$ & $28.13 \pm 9.42$ & $\mathrm{p}<0.001$ \\
HAQ (Health) & $60.83 \pm 8.43$ & $28.13 \pm 8.45$ & $\mathrm{p}<0.001$ & $25.63 \pm 10.56$ & $\mathrm{p}<0.001$ \\
\hline
\end{tabular}

Data presented as Mean \pm standard deviation. ${ }^{*} \mathrm{p}=$ not significant for any parameter when compared for changes from week 24 to week $48 . \wedge \mathrm{p}=0.006$ as compared to week 24 for rise in ESR during the bADA free period.

Conclusions: Biosimilar adalimumab therapy was effective in treating AS patients. The disease activity and health assessment scores continued to remain stable with no worsening after the stoppage of treatment for 6 months, indicating a post-therapy effectiveness in these patients with no reported adverse event.

\section{References:}

[1] Bandyopadhyay S, et al. Biosimilars. 2015;5:1-18.

[2] Jani RH et al. int J Rheum Dis. 2015 Jul 14.

Disclosure of Interest: None declared

DOI: 10.1136/annrheumdis-2017-eular.3825

\section{AB0706 ANKYLOSING SPONDYLITIS PATIENTS WITH UVEITIS HAD BETTER ADALIMUMAB RETENTION RATE: HUR-BIO REAL LIFE RESULTS}

B. Armagan ${ }^{1}$, A. Sari ${ }^{1}$, A. Erden ${ }^{1}$, L. Kilic ${ }^{1}$, D.C. Guven ${ }^{2}$, T. Pashayev ${ }^{2}$, E. Bilgin ${ }^{2}$, C. Simsek ${ }^{2}$, E.C. Erdat ${ }^{2}$, O. Karadag ${ }^{1}$, A. Akdogan ${ }^{1}$, S. Apras Bilgen $^{1}$, S. Kiraz ${ }^{1}$, I. Ertenli ${ }^{1}$, U. Kalyoncu ${ }^{1} .{ }^{1}$ Hacettepe University, Department of Internal Medicine, Division of Rheumatology; ${ }^{2}$ Department of Internal Medicine Hacettepe University, Ankara, Turkey

Background: Retention of biological drugs in inflammatory arthritis may be affected from different obvious and unknown factors. It can be related with patient characteritics or disease features. In ankylosing spondylitis (AS), retention rate of biological drugs may be related with extra-articular presentation of AS such as uveitis, as well.

Objectives: The objective of this study was to assess whether uveitis affected retention of adalimumab in AS patients in our single center biological cohort.

Methods: Hacettepe University Biological registry is single-center biological registry since 2005. HURBIO had 2165 spondyloarthritis patients of which 1190 patients had AS according to NY criteria. Until now, in 510 of 1190 patients have used adalimumab and 350 of 510 patients had available for uveitis. Patients 